\title{
CRÍTICA A LA BIBLIOGRAFÍA GIMNÁSTICA DE LA EDUCACIÓN FÍSICA PUBLICADA EN ESPAÑA (1801-1939)
}

\author{
Xavier Torrebadella Flix* \\ Universidad Autónoma de Barcelona
}

\begin{abstract}
Resumen: En este trabajo se han tratado referencias historicistas que abordaron cuestiones en torno a la bibliografía gimnástica de la educación física española entre 1801 a 1939. El objeto de estudio se ha centrado principalmente en el análisis de las obras propias de la materia. Las noticias referenciales se exponen y se comentan en orden de aparición cronológica. Singularmente, las referencias y las opiniones que hemos localizado en estas obras, nos ayudan a interpretar mejor el estado de la cuestión y apreciar la importancia que tuvieron las pocas aportaciones literarias para el desarrollo social e institucional de la gimnástica y la educación física en el desierto bibliográfico que las propias disciplinas generaron.

Palabras clave: bibliografía; crítica bibliográfica; educación física; gimnástica; deporte.
\end{abstract}

Title: REVIEW OF THE GYMNASTICS BIBLIOGRAPHY IN THE PHYSICAL EDUCATION PUBLISHED IN SPAIN (1801-1939).

Abstract: This article is about historicist references regarding the bibliography of gymnastics in the Spanish physical education between 1801 and 1939. The purpose of the study has been mainly the analysis of the books about this topic. The referential news are stated and discussed in chronological order. Singularly, the references and opinions that we have found in these books, help to better understand the state of the question and to better appreciate the importance that the few literary contributions had in the social and institutional development of gymnastics and physical education in the bibliographic desert that these disciplines themselves created.

Keywords: bibliography; critical bibliography; physical education; gymnastics; sports.

\section{INTRODUCCIÓN.}

En trabajos anteriores hemos tratado la producción bibliográfica española de la educación física y el deporte entre 1801 y 1939. Las aportaciones se han centrado en estudios bibliométricos, bio-bibliográficos y en presentar un repertorio bibliográfico (Torrebadella, 2000a, 2009 y 2011b; Torrebadella y Olivera, 2012). Ante los resultados y las valoraciones de los trabajos precedentes, hemos concluido que la producción bibliográfica en torno a la educación física fue relativamente escasa. Esta percepción

*xtorreba@gmail.com

Recibido: 24/09/2012; 2a versión: 17/11/2012; aceptado: 13/12/2012.

TORREBADELLA FLIX, X. Crítica a la bibliografía gimnástica de la educación física publicada en España (1801-1939). Anales de Documentación, 2013, vol. 16, $\mathrm{n}^{\mathrm{o}} 1$.

Disponible en: http://dx.doi.org/10.6018/analesdoc.16.1.158851 
también fue puesta de manifiesto por algunos de los autores de las obras literarias, técnicas y científicas que nos ocupan. Sin embargo, aparte de considerar la información de los repertorios bibliográficos de la época: Museo Pedagógico Nacional (1915), Rufino Blanco (1927) o el Catálogo de la Biblioteca del Gimnasio de Colón de Amadeo Llaverías (1935); un análisis de las referencias historicistas en torno a las cuestiones de la bibliografía, identifican la contribución al proceso de legitimización académico de la materia (Torrebadella, 2009). Ello permite, que a partir de estas informaciones, podamos interpretar mejor y reconstruir la percepción que existió en cuanto al uso y la valoración de la bibliografía gimnástico-deportiva de la educación física en la época.

En el estudio que Miguel Piernavieja (1962, p. 143) realizó sobre la bibliografía gimnástica decimonónica, ya apreció las primeras objeciones críticas en torno a la producción y la calidad: "La bibliografía gimnástica decimonónica no es muy rica ni, sobre todo, valiosa. Le faltó principalmente la búsqueda de los valores tradicionales españoles e intentar una adaptación a las corrientes extranjeras a nuestras condiciones y circunstancias".

Indudablemente creemos que la crítica de Piernavieja fue acertada. Y como indica Bertha Gutiérrez (1995, p. 438): "La educación física en España, a lo largo de este siglo, no fue un tema de interés". Sin embargo, nosotros podemos ser más contundentes y añadir que la bibliografía gimnástica decimonónica fue poco abundante, rutinaria y superficial. Aunque la bibliografía nacional -en algunos casos excepcionales-, trató de sustentar un carácter genuino, finalmente fracasó. Nuestra bibliografía más bien se reprodujo, se asimiló o se copió de lo foráneo, incorporó una poca y débil discusión doctrinal y, apenas, vislumbró un cierto alcance científico.

\section{MÉTODO Y MATERIAL.}

La fundamentación metodológica de este estudio tiene como base los trabajos biobibliográficos y el repertorio de la educación física y el deporte presentados por el autor, que estudian in situ las obras de la educación física y el deporte español del siglo XIX y primer tercio del siglo XX (Torrebadella, 2009 y 2011b; Torrebadella y Olivera, 2012). La naturaleza histórica y documental de la investigación transita de la fase heurística localización de las fuentes bibliográficas-, al análisis crítico de contenidos con el que se fija la clasificación documental obras (Torrebadella, 2009). Un vaciado y selección de las referencias históricas objeto de estudio y un análisis hermenéutico o interpretativo, construido a partir del soporte de las propias referencias historicistas de los obras entre el período de 1801-1939, la prensa de noticias de la época, la prensa específica de la gimnástica o educación física (Torrebadella, 2012a) y algunos estudios recientes, facilitan y complementan el relato cronológico que se presenta. Las fuentes bibliográficas consultadas parten principalmente de los catálogos históricos específicos (Museo Pedagógico Nacional, 1915; Blanco, 1927; Llaverías, 1935). Los principales fondos documentales consultados han tenido como referencias ineludibles la Biblioteca del Consell Català de l'Esport -Generalitat de Catalunya- la Biblioteca de la Facultad de 
Ciencias de la Actividad Física y el Deporte de la Universidad Politécnica de Madrid, la Biblioteca Digital Hispánica, la Hemeroteca Digital de la Biblioteca Nacional y el archivo privado del autor (Torrebadella, 2009).

\section{NOTICIAS REFERENCIALES A LA BIBLIOGRAFÍA DEL SIGLO XIX.}

La primera obra que se incorporó en el álbum bibliográfico de la educación física escolar española fue la de los franceses Durivier y Jauffret (1807), La gimnástica o escuela de la juventud, basado en el método de educación física de Guts Mhuts (17591839). Sin embargo, con el regreso del absolutismo de Fernando VII esta obra se rehusó por afrancesada, aunque fue tomada como referencia en la Descripción de los juegos de la infancia, del maestro de primeras letras Vicente Naharro (1818), la primera obra nacional de la educación física dedicada a la primera enseñanza (Torrebadella, 2011c). Posteriormente, la Gimnástica del bello sexo (1822) fue una singular obra anónima publicada en Londres, que hemos atribuido al literato liberal José Joaquín de Mora (Climent, 2001; Gutiérrez, 1994). En ella se presentaban juegos y recreaciones corporales, que junto a unas lecciones higiénico-morales, deseaban contribuir a la educación física privada de las jóvenes. Lamentablemente, a lo largo de todo el siglo XIX la educación física femenina y la gimnástica, a excepción de unos pocos médicos y pedagogos, paso inadvertida y sin interés público, por lo que apenas existieron publicaciones al respecto (Torrebadella, 2011a).

Tras estas publicaciones, un largo paréntesis de un período ominoso de involución mutiló todo proyecto cultural y científico. Ante la falta de una literatura gimnástica propia, inclusive, de alguien que encabezara un proyecto como el que Francisco Amorós (1770-1848) lideraba en Francia, las obras propagandísticas del conde de Villalobos (1842 y 1845), no hacían más que evidenciar la desolación y el estado de decadencia de la educación física española como ya hacía décadas se estaba denunciando (González, 1814).

Ante la popularidad del Manuel d'éducation physique, gimnastyque et morale (1830) de Francisco Amorós y sus reiteradas ediciones, conocemos que inclusive el comandante José Cataumber Rosell se ocupó de la traducción de la obra elemental de Amorós: Educación física, gimnástica y moral. Sobre este asunto se citaba en la prensa, que era ciertamente extraño, que hasta la fecha, a nadie se le hubiera ocurrido traducir el importantísimo libro del Sr. Amorós (Gacetilla de la capital, 1845). Lamentablemente tal probabilidad nunca llegó a suceder y desconocemos las causas por las que no se publicó la obra que parecía estar bastante adelantada. Para volver a encontrar una obra que tratase de gimnástica y, que no fuese de uso propagandístico, se tuvo que esperar hasta la aportación de Francisco Fernández Villabrille (1849).

El inspector de primera y segunda enseñanza Laureano Figuerola (1844, p. 171), se lamentaba de que no existiera ninguna obra que tratase sobre la educación física y la 
gimnástica, aspecto que era de una absoluta necesidad. Así citaba que para "la educación física no ha parecido todavía guía alguna, que por su valor intrínseco ejerza autoridad”.

Por tanto, podemos admitir como cierta la apreciación de Bertha Gutiérrez (1995, p. 438) cuando cita que la educación física en "la primera mitad del Ochocientos, salvo a unos cuantos 'iniciados' no le interesó a nadie, y sobre todo, no les interesó a los médicos. Los pocos que escriben sobre sus beneficios son pedagogos o literatos y los que la ponen en marcha militares".

Pasaban los años y en España aún no se había publicado ninguna obra que atendiese debidamente la gimnástica. En 1852 el capitán Aparici incorporó la Instrucción para la enseñanza de la gimnástica en los cuerpos y establecimientos militares, una traducción del reglamento de instrucción gimnástica del ejército francés, que había sido aprobado recientemente. Un año más tarde, la prensa madrileña mencionaba que el Sr. de Salamanca, hijo del Sr. conde de Campo-Alange, oficial del Regimiento de Infantería de la Princesa, instalado en Madrid, había llevado a imprenta un tratado de ejercicios gimnásticos con láminas ilustradas de movimientos y figuras (Noticias generales, 1853, p. 3). Lamentablemente de esta obra no tenemos otra noticia que la citada.

Las necesidades del momento hicieron que se publicasen algunos opúsculos gimnásticos como el de Borja Ramírez (1856), Elementos de gimnasia; un sencillo manual dedicado a cubrir la educación física de los alumnos en base al método gimnástico de Amorós. Sin embargo, todavía no se había publicado ninguna obra de calidad, como las que ya circulaban por Europa. Al respecto, el conde de Villalobos (1858) citaba la necesidad de incorporar en la inexistente bibliografía de nuestra gimnástica la traducción de las obras francesas, alemanas y suecas.

Otra obra de esta época, que solamente tenemos noticias por Llaverías (1935, p. 7), fue Nociones de gimnástica (1859) del leridano Carlos Amat; una obra que más tarde fue plagiada por Nicolás Camús (1885), que según cita Dalmau (1947, p. 46) de "todas maneras, el libro se vendió mucho y Camús realizó, con la edición, un excelente negocio". Más descarado todavía, es que la obra de Amat también fue un plagio de un capítulo del tratado de Higiene Privada del conocido Pedro Felipe Monlau (1846). Dos años después se incorporó el Manual popular de Gimnasia de Sala del Dr. Schreber (1861), la obra de mayor influencia en la gimnástica médica y doméstica de todo el siglo XIX (Torrebadella, 2009).

Durante la década de los sesenta se añadieron los primeros tratados gimnásticos nacionales que marcaron un relativo alcance técnico-práctico: Moratones (1863), Busqué (1865), Carlier (1867) y Lladó (1868). Coincidimos con José Climent (2001, p. 70), cuando afirma que este período la "literatura gimnástica sufrió una eclosión inusitada" en la que también participó el colectivo médico que promovió la temática en programas de doctorado (Torrebadella, 2012b). En cuanto a la posibilidad de disponer de alguna obra nacional de cierta calidad, apenas citar el pequeño manual Nociones elementales de 
gimnasia de Antonio Moratones (1863), publicado en Barcelona. José Luis Hernández (1988, p. 52) comprueba que en España existían obras enteramente plagiadas de Amorós, como la de Moratones que "muestra una burda copia de la obra de Amorós en la que incluye 77 figuras exactas a las del Atlas de nuestro autor".

Más tarde, el mismo conde de Villalobos (1865, p. 257) decía tener pendiente un "extenso trabajo será parte de una obra terapéutica gimnasiológica que pensamos publicar más adelante". Este mismo año se publicaba el tratado de Busqué (1865), Gimnástica higiénica, médica y ortopédica o el ejercicio considerado como medio terapéutico, considerado como la primera obra nacional de la gimnástica médica decimonónica (Climent, 1989).

Con la muerte del conde de Villalobos en julio de 1867, se perdió al hombre, pero también su obra. Al erudito gimnasiarca le faltó un tratado que estuviese a la altura de sus realizaciones prácticas, objetivo que, según Ordáx (1882, p. 10-11), parece ser que estuvo a punto de alcanzarse: "quedaron sumidos en el olvido sus estudios, afanes y desvelos por algún tiempo", y tan sólo quedó el manuscrito de una obra inédita y voluminosa con el título de Gimnasia interior. Conocemos que esta obra trataba "sobre la historia crítica de la gimnasia como ciencia antigua de la curación y conservación del hombre por los arreglados ejercicios del cuerpo" (Revista bibliográfica, 1867, p. 84). Sin embargo, a pesar de los esfuerzos de sus hijos por intentar publicar la obra, ésta jamás vio la luz.

En unos años en que la popularidad de la gimnasia tomó cierto crédito instalándose los primeros gimnasios higiénicos en las grandes ciudades españolas: Barcelona, Madrid, Bilbao, Sevilla o Valencia, surgieron eventuales tratados gimnásticos que se presentaron como aportaciones auténticamente innovadoras y sugerentes. Los tratados de Pedro Carlier (1867), Joaquín Lladó (1868) testimonian esta incipiente época empírica de los primeros gimnasios. Mientras tanto se sucedían algunas estériles aportaciones propagandísticas en el ámbito de la medicina y de la higiene que, apenas trascendieron de la anécdota y repetitiva retórica (Flecha, 1992; Torrebadella, 2012).

Apenas existían proyectos para traducir obras extranjeras de calidad. Una aislada aportación fue La salud del espiritu y del cuerpo por la gimnasia, del francés Eugenio Paz (1867, p. 14) que se añadía a las pocas voces propagandísticas en la divulgación gimnástica: "He escrito este libro con el objeto de popularizar la gimnasia y de hacer conocer los inmensos servicios que está llamada a prestar a la humanidad, si se quiere, en fin, concederle el puesto que le está señalado en la educación”. El gimnasiarca Pedro Carlier (1867, p. 8) en Tratado de gimnasia médica y civil se refirió precisamente a poner en evidencia a los tratados que fuera de España eran copiados "la mayor parte casi literalmente, con excepción de alguna que otra reforma o innovación, que han considerado conveniente para disfrazar algo el plagio, del que escribió el citado coronel Amorós en París". Ciertamente, la afirmación de Carlier era real. Incluso él mismo introdujo en su libro tres páginas, copias literales, de la obra de Schreber (1861) y reprodujo unas láminas de aparatos como las de Amorós, y para no ser idénticamente las mismas, realizó algunos 
retoques. Carlier consideraba su Tratado como el mejor que hasta la fecha se había escrito en España, incluso admitía que había adelantado y mejorado la obra de Amorós.

En el apéndice bibliográfico de la obra La Gimnástica Cristiana del Dr. Letamendi (1876), se citaban como bibliografía nacional las obras de Busqué Torró (1865), Joaquín Lladó (1868) y Salvador López (1873). Así comprobamos como en esta obra no se destacaba la bibliografía nacional, puesto que de 112 referencias, solamente se citaban las tres obras aludidas anteriormente. No obstante, debe apreciarse el interés de la bibliografía de Letamendi, ya que no se ha encontrado en ninguna otra obra decimonónica tanta información documental sobre la gimnástica ${ }^{1}$. Generalmente, las obras del siglo XIX apenas citaban bibliografía. Deberemos esperar al siglo XX para encontrar algún que otro incorrecto anexo bibliográfico.

Pasan los años y la bibliografía gimnástico española prácticamente permanece inalterable, y solo se completa con las obras El Gimnasio del sevillano Salvador López (1873) - puesto a la venta por fascículos sueltos previa inscripción- y Elementos de educación física de José del Campo (1878), ambas enteramente representantes del método de Francisco Amorós. En esta última se aludía a la poca bibliografía existente sobre la enseñanza gimnástica. José del Campo (1878), además de criticar la escasez de obras, se lamentaba de lo poco útiles que eran las que hasta la fecha existían: "Aunque pocos, también existen algunos libros que se ocupan de los ejercicios y métodos de enseñanza; pero unos por superficiales y otros por demasiado complicados, no llenan en nuestra humilde opinión, el laudable fin que sus autores se propusieron" (p. 11).

Otra obra de la que apenas tenemos referencia es una menoría de Pilar Pascual (1880) sobre la Importancia de la educación física de las niñas (Criado, 1889, p. 130 y 135). Probablemente tenga como base los artículos que con el mismo título fueron publicados entre 1870 y 1871 en el Monitor de primera enseñanza (Cortada, 1992).

En 1882 El Gimnasta Español, "revista consagrada a la gimnástica en todas sus aplicaciones", ofreció en sus dos primeros números una memoria bibliográfica de obras extranjeras y nacionales publicadas hasta 1877 (Publicaciones importantes, 1882a y 1882b). En esta memoria se citan 39 referencias aludidas como publicaciones importantes: 17 en idioma francés, 14 en italiano y, sólo 9 en español ${ }^{2}$. Estos datos ya son indicaciones contundentes sobre el considerable déficit de la literatura gimnástico-técnica nacional. En cerca de 80 años apenas se habían editado una decena de obras. Por eso, a partir de la fecha surgieron algunos tratados que se autoproclamaron como los primeros o más importantes en su ramo. La obra de Francisco Pedregal (1884, p. 93), Gimnástica Civil y militar fue considerada por el propio autor como la primera empresa editorial importante publicada hasta la fecha: "Nuestra obra adolecerá, sin duda, de muchos defectos; pero tenemos la satisfacción de que sea la primera en España que abarca todos los ejercicios gimnásticos, ordenados debidamente, explicados cada uno con la necesaria extensión y con el grabado que corresponde". 
El gimnasiarca barcelonés Joaquín Ramis (1888, p. 12) criticaba que aún no se había publicado ningún libro que tratase el arte de la gimnástica con el rigor científico suficiente: "la falta de método de que adolece el arte; pues no existe libro alguno que enseñe, o haga ver siquiera lo que significa, y lo que de su ejercicio puede esperarse". Posteriormente, una referencia de José Sánchez (1894, p. 17) argumentaba que el "primer libro de Gimnasia pedagógica que se publicó en España fue la primera edición de este Tratado en 1883". Aunque también reconocía que anteriormente al suyo se habían publicado otros tratados de Sebastián Busqué (1865), Schreber (1861) Salvador López (1873) y, un año después, el tratado de Francisco Pedregal (1884).

En el ámbito pedagógico, podemos advertir que, tanto Francisco Pedregal, como José Sánchez, parecían no conocer, o al menos obviaron las referencias de varias obras anteriores a las suyas como las de Vicente Naharro (1818), Joaquín Lladó (1868) o José del Campo (1878).

Como comprobaremos, a la bibliografía española le faltó identidad, que por otro lado, quizás no fuera tan necesaria. No obstante, la bibliografía autóctona se complementó editorialmente y científicamente con unas pocas obras extranjeras publicadas en España. Como ya vamos adelantando, pareció existir un menosprecio a la bibliografía nacional, considerando más oportuno la consulta de autores extranjeros, sobre todo franceses. Así lo entendía el Dr. Bejarano (1886, p. 53-54), que sobre las cuestiones de educación física forzosamente confesaba que "no estamos a la altura de otros países, que, como Bélgica y Francia, por ejemplo, se preocupan grandemente de tales asuntos, a los que consagran multitud de publicaciones interesantísimas en España casi desconocidas".

Publicar en España era en aquella época una empresa arriesgada y todavía más, si no existía una verdadera aceptación popular de la gimnástica. Ello quedó demostrado en la gesta del bilbaíno Felipe Serrate (1887), que tuvo que sufragar encarecidamente los gastos de su Tratado, ofreciéndolo por artículos en la revista Ilustración Gimnástica (18861887), fundada y dirigida por él mismo (Vitoria, 1999).

Las evidencias de la falta de una bibliografía gimnástica especializada se hacían sentir con el Manual de gimnástica militar del teniente Antonio Álvarez (1889, p. 2) publicado con el objeto de ofrecer una guía de formación física y de utilidad práctica para sus compañeros "en un ramo tan necesario y del que tan poco se ha escrito, y que parece volver a recobrar la gran importancia que tuviera en la antigüedad". En otro campo, el profesor de la Universidad de Oviedo Adolfo Álvarez Buylla (1890, p. 54) se lamentaba del abandono generalizado de la educación física incidiendo especialmente, en la falta de libros que tratasen con el debido rigor un tema y un problema tan importante: "todavía no ha llegado para nuestra patria el momento en que la opinión, ahíta de la importancia de la Educación Física, se manifieste en serios libros".

Asimismo, en el Congreso Pedagógico Nacional, de 1892, Concepción Arenal (1929, p. 364), no solamente indicaba la necesidad urgente de incorporar la educación física en 
las escuelas, sino que, además, advertía que ésta campaña sería estéril si no iba acompañada de otra que acercase a la población libros de divulgación en la materia: "Lo aprendido en las escuelas sería letra muerta, al menos por mucho tiempo, si fuera de ellas no recibía un apoyo eficaz con la publicación de libros y de cartillas que generalizaran conocimientos, de que hoy carecen aun las personas muy ilustradas en otros conceptos".

En las obras del Dr. Esteban García Fraguas se aprecian algunas alusiones en torno a la bibliografía española. El Dr. García Fraguas (1892b, p. 31) enumeraba algunas de las más representativas aportaciones de la literatura gimnástico-deportiva como los ya citados tratados de Busqué y Torró, Sánchez Somoano, Pedregal y Prida, pero también añadía "numerosos tratados de esgrima, equitación y caza, entre los que se hallan los del marqués de Heredia, Hidalgo y otros cuyos nombres no recuerdo en este momento" y otros trabajos literarios de Salvador López Gómez, Marcos Ordax, David Ferrer, Eugenio Fernández o Marcelo Sanz. En otra obra García Fraguas (1893, p. 164) ofrecía una referencia de veintiséis autores que, según él componían la bibliografía española en torno a la gimnástica: “Aparici, Busqué, Lladó, Salvador López, David Ferrer, Sánchez Somoano, Pedregal, Alcántara García, Giner de los Ríos, Altamira, Cossió, Rubio, Cucala, marqués de Heredia, Merino, Merelo, Salillas, Abad, Fraguas, Decref, Peña y Goñi, Pulido, Tolosa Latour, Calatraveño, Vega-Rey, Amorós y Broutin”. Sin embargo, García Fraguas (1894, p. IX-X), en advertencia a los alumnos y profesores, criticaba la producción bibliografía gimnástica española, por la falta de originalidad, la falta de rigor, las malas traducciones y los continuos plagios de los que llamaba "titiriteros y mercaderes de la Gimnasia" y se lamentaba de "la falta de un tratado de gimnasia racional, escrito por médicos y pedagogos prácticos y teóricos”.

Precisamente ha sido en una de las obras del Dr. García Fraguas, en la que hemos podido localizar un segundo apéndice bibliográfico decimonónico. En Programa razonado de gimnástica higiénica y juegos escolares (1892a), introdujo una extensa bibliografía de obras y autores (españoles y extranjeros; cien en total) admitiendo que los libros citados fueron consultados para elaborar la redacción del Programa. Entre toda esta bibliografía se citan: Sebastián Busqué (1865), Juan Giné (1871), José Merelo (1878), Salvador López (1881), José Monlau (1881), José Sánchez (1883), David Ferrer (1883), Francisco Pedregal (1884), Guillermo Deping (1886), Hidalgo Terrón (1889), García Fraguas (1892), Montserrate Abad (1892), Marqués de Heredia (1892), Peña y Goñi (1892), y los Programas Oficiales de la Escuela Central de Gimnástica (1887) ${ }^{3}$.

El sevillano Salvador López (1894) redactó un manual de texto de ejercicios gimnásticos. En él demuestra un importante conocimiento de las fuentes extranjeras -citas a pie de página-, sobre todo de autores franceses ${ }^{4}$, aunque también citó obras de autores españoles como José Letamendi (1876), Ronquillo -en Joaquín Lladó- (1876), García Fraguas (1894), David Ferrer (1883), Alejandro San Martín (1893), José Calatraveño (1893) o León Broutin (1894). 
En este año la Asociación de Profesores Oficiales de Gimnástica presentó las bases para establecer un concurso al que sólo podían acudir profesores oficiales para premiar la obra que mejor se adaptase a "la enseñanza oficial de la gimnástica y entendiendo que no existe actualmente ningún texto con la competencia necesaria o con las condiciones de brevedad que exige la enseñanza de la Gimnástica conforme se halla planteada actualmente en los Institutos" (Un concurso útil, 1894, p. 55). Sin embargo, las bases del concurso quedaron anuladas debido a la Circular 18 de marzo de 1894 sobre las "Normas para la enseñanza de la gimnástica" de Eduardo Vincenti, director general de Instrucción Pública, que declaró prohibidos los libros de texto (Marín, 2009). Probablemente este concurso incentivó la publicación de algunos de los tratados de la época, que además incorporaron las orientaciones curriculares de la Circular (López, 1894; Pedregal, 1895; Sanz, 1895).

Finalmente, hemos de estimar de oportunas contribuciones las obras traducidas por Ricardo Rubio - uno de los máximos representantes del movimiento de regeneración física en la Institución Libre de enseñanza- de los doctores franceses Fernando Lagrange (1894 y 1896), Ph. Tissié (1899) y del italiano Ángel Mosso (1894). Estas obras aportaron nuevos conocimientos y bases científicas a la comprensión de la educación física moderna (Torrebadella, 2009).

Hasta aquí llegaron las referencias historicistas de la bibliografía gimnástica de la educación física decimonónica. Así encontramos que, sobre la bibliografía autóctona y propia, apenas existieron comentarios laudables, puesto que muy poco había para ser comentado, cuando ésta apenas revelaba suficiente fundamentación pedagógica, científica y técnica.

\section{REFERENCIAS BIBLIOGRÁFICAS EN EL PRIMER TERCIO DEL SIGLO XX.}

En el siglo XX (1901 a 1939), la incorporación de apéndices bibliográficos o citas bibliográficas, en término general y salvando algunas pocas y raras excepciones, continuó en la misma trayectoria del siglo anterior, es decir brilló por su ausencia. Las críticas que aludían al desierto bibliográfico de la educación física fueron recurrentes. Narciso Masferrer (1902, p. 541) hacía una crítica a "la biblioteca gimnástica, que tan pocos volúmenes buenos atesora". En 1906, Los Deportes comentaba que en Barcelona ya se podían localizar algunas obras en torno a la gimnástica. Asimismo se lamentaba que la Biblioteca popular de los Manuales Soler, que ya llevaba publicados 65 tomos, todavía no había publicado ningún tratado de gimnástica: "Cada día son más numerosas en Barcelona las librerías que poseen en venta las obras relacionadas con el estudio de la gimnástica. No hace muchos años que nos hallábamos con libreros que estaban en la creencia de que nada había publicado tocante a este arte" (Gimnasia, 1906a, p. 894).

En Barcelona el Gimnasio de Colón, propiedad de Amadeo Llaverías, acumuló una prodigiosa biblioteca gimnástico-deportiva y de temas afines, que podía ser consultaba 
públicamente (Fusté, 1997). En 1905 la revista Los Deportes ofreció un informe detallado de una gran parte del contenido, que paso a ser catalogado en 1910 con 1.021 registros, y que posteriormente fue completado por el librero Antonio Palau en 1935 hasta alcanzar los 2.917 registros (Llaverías, 1905a, 1910 y 1935). El Gimnasio de Colón tenía por costumbre organizar certámenes literarios en torno a la educación física, obsequiando a los premiados la oportunidad de publicar las obras. En el certamen de 1905 se elevó la calidad de los participantes puesto que en las bases se pedía ser autor de alguna obra o artículo "relativo a la gimnasia o a conocimientos afines", y de poseer el título de profesor oficial de gimnástica, para acceder al premio nacional (Llaverías, 1905b, p. 282).

Sin embargo, con el repentino cierre del Gimnasio de Colón en 1906, Amadeo Llaverías depositó su extensa y valiosa biblioteca en la dirección de la revista Los Deportes. Aprovechando la oportunidad, la revista realizó una campaña de difusión de los conocimientos útiles de esta Biblioteca, por lo que obsequió con un ejemplar a todos los que acudieron a la imprenta Los Deportes -c/ Valencia, 200- acompañados con un talón que se publicaba en la sección de anuncios (Deportes, 1906b). Así, desde el día 22 al 27 de octubre se regalaron libros, uno por persona: "a elegir entre varios de los que figuraban en la Biblioteca Circulante del Gimnasio de Colón de Barcelona" (Deportes, 1906a, p. 734). Años más tarde, Amadeo Llaverías (1910) puso a la venta el famoso Catálogo de la Biblioteca del Gimnasio de Colón. En 1925 el librero Antonio Palau ya vendía la Biblioteca por 20.000 pesetas (Palau, 1925), que finalmente compró la Generalitat de Cataluña diez años más tarde (Fusté, 1997; Berasategui, 1998 y 2008; Torrebadella, 2009).

De la traducción realizada al castellano por el profesor Francisco de la Macorra de la obra de M. Soleirol de Serves y Mme. Le Roux, Manual de gimnasia racional y práctica (método sueco), editado por la antigua Casa editorial Bailly-Bailliere e hijos, la revista Los Deportes citaba: "creemos que dicha obrita tendrá tanto éxito o más favor que la de D. G. M. Schreber, de la que durante 45 años tantas ediciones llevan lanzadas al mercado estos inteligentes como sagaces libreros" (Gimnasia, 1906b, p. 917).

En el estudio pedagógico de Antonio Casas (1910), descubrimos la primera obra en incorporar citas bibliográficas y un apéndice de referencias recomendando para el estudio de la educación física. Como la nómina de referencias es poco precisa, añadimos el nombre completo de algunos de los autores más representativos: Alejandro Sanmartín, Mariano Carderera, Dr. García Fraguas, Dr. Nicasio Mariscal, Salvador López, Martí Alpera, P. de Alcántara García, Concepción Arenal, Joaquín Lladó, Francisco Pedregal, José Sánchez de Somoano, Ezequiel Solana, Dr. López Ocaña, Pablo Montesino, Manuel Ballesteros o Joaquín Rius.

Años más tarde, el periodista deportivo Ricardo Ruíz dejó constancia de la tendencia que se detectó a partir de 1914 en incorporar obras extranjeras al castellano. No obstante, adviértase que el distinguido periodista anotaba la falacia que ello suponía. Así tras haber ignorado durante mucho tiempo las obras y métodos de educación física extranjeros, en 
esos momentos, aparecían nuevas incorporaciones con el objeto de recuperar el terreno perdido. Con una objeción eminentemente crítica, Ricardo Ruíz rescataba del olvido, cuarenta años más tarde de su primera edición, La gimnasia razonada, una traducción de la obra del gimnasiarca francés Eugenio Paz (1917). Ricardo Ruiz comentaba que a raíz de la Gran Guerra había surgido en España una tendencia en argumentar la necesidad de "desempolvar libros de la moderna ciencia gimnástica, y dedicarse en adelante al apostolado de la educación física” (Paz, 1917, p. 1-2).

El Museo Pedagógico Nacional (1915) ofreció un pequeño catálogo Notas sobre material de enseñanza, con el que orientaba al maestro y a la escuela de primera enseñanza de la bibliografía necesaria para cada una de las asignaturas escolares. En las recomendaciones sobre educación física e higiene escolar, solamente se citaban dos obras de autores españoles: Pedro de Alcántara García, De las teorías modernas acerca de la educación física (1886) y Saimbraum, Teoría y práctica de la gimnasia respiratoria aplicada a la vida escolar y a la vida doméstica (1911). Las demás obras pertenecían a autores extranjeros traducidos en España como Kumlien, Lagrange, Mosso o Tissié.

En este momento ya podemos adelantar la pregunta ¿de por qué en la citada obra se recomendaba una bibliografía española tan escasa?

Augusto Condo (1919, p. 30) en la revista La Educación Física criticó la empobrecida producción de libros nacionales que se ocupasen de la educación física "a pesar de tener como fronteriza una nación en la cual la bibliografía sobre la materia que nos ocupa es realmente enorme, pues por miles se pueden contar las obras en Francia".

Así pues, parece ser, como ya se iba advirtiendo, que a la falta de una bibliografía autóctona capaz de ofrecer respuestas pedagógicas, científicas e incluso prácticas, se tuvo que recurrir a la bibliografía extranjera, ya fuera traduciendo las obras, o bien, incorporándolas en la lengua original (Torrebadella, 2011b).

Otras obras en las que se añadieron apéndices bibliográficos fueron las de Bernardo Carrascal (1923), Eduardo Alfonso (1925) y José Villalba (1927). Carrascal (1923), doctor en medicina y profesor de gimnástica de Zamora, afirmaba que la bibliografía que había utilizado representaba las fuentes documentales consultadas para la elaboración de su tratado. Se comprueba que de los veintisiete registros citados, catorce títulos se ocupaban específicamente de la educación física o la gimnástica: Bellí, Decref (tres títulos), Spitzy, Gulick, Kumlien, López Carmona, López Gómez (Manual de ejercicios gimnásticos) Mosso (La fatiga), Saimbraum (Teoría y práctica de la gimnástica respiratoria), Sanz Romo (Higiene de la educación física) y Tissié (La fatiga y el adiestramiento). El resto de las obras citadas corresponden a tratados generales de fisiología, anatomía e higiene.

El Dr. naturista Eduardo Alfonso (1925) aconsejaba como libros de gimnasia doméstica algunas de las obras más populares publicadas en España. Mencionaba las 
obras del danés Muller: Mi sistema, El libro del aire libre, Mi sistema para señoras, Mi sistema para niños; las obras del Dr. Saimbraum, Salud fuerza y belleza, por medio de la gimnasia sueca, Teoría y práctica de la gimnasia respiratoria y La Gimnasia de las profesiones; de Willian Blaikie, Para ser fuertes; del Dr. Arnulphy, La salud por la respiración; de Soleirol de Serves y Le Roux, Manual de gimnástica racional, y de Vicente Romero, Cartilla compendio de gimnasia racional a pie firme y manos libres (Torrebadella, 2011).

Joaquín de Aguilera (1928, p. 61), tras un viaje por Europa comisionado para el estudio de la gimnástica reconoció que en España existía "desgraciadamente, escasa bibliografía de esta clase, y pocos son los que a este asunto se dedican". Ante el problema recomendó que se concediese una mayor importancia a la divulgación escrita de la educación física, tal y como se hacía en los países visitados: "por medio de la prensa diaria, por medio de series de conferencias encomendadas a personas de reconocida competencia y entusiastas en la resolución de cuestión de tanto interés, o ya abriendo concursos para premiar obras en que se tratara de ella" (Aguilera, 1928, p. 61).

José Villalba (1927), en una memoria de estudio sobre la educación física en el extranjero incorporó una interesante bibliografía de obras escritas en Alemania, Italia, Francia, Checoslovaquia, Inglaterra, Estados Unidos, Bélgica, Dinamarca, Portugal Suiza, Suecia, Grecia, Argentina, Austria y España. Entre las obras publicadas en España por autores españoles, tan sólo se citan nueve fuentes: Marcelo Sanz (1895), Julián de las Barreras (1900), Joaquín Decref (1913), Dr. Saimbraum (1913), Lorenzo Niño (1913), Marcelo Sanz (1915), Isaías Bobo-Díez (1917) y Rodrigo Suárez (1925). El resto de títulos pertenecen a varios de los autores extranjeros que publicaron en España (Torrebadella, 2009 y 2011): Ángel Mosso (1894) Fernando Lagrange (1894, 1895 y 1896), Ph. Tissié (1899), Arnulphy (1908), Kumlien (1913), Eugenio Paz (1917), W. P. Welpton (1917), Hans Spitzy (1917), Demeny (1917), L. Halsey Gulick (1918), Berthier (1920), Max Parnet (1921), Ketty Jentzer (1921), Montefiore (1921) y G. Hebert (1925).

Completando el estudio, otro dato relevante se encuentra en la bibliografía que ofrece la Enciclopedia Universal Ilustrada de Espasa-Calpe (1925, p. 72-88). Al localizar la palabra "gimnasia", uno se encuentra con una amplia información de varias páginas y en el último apartado, en el que se cita una bibliografía, sobre la materia tan sólo figura una obra española entre 36 citas extranjeras. Se trata del Tratado racional de gimnástica y de ejercicios corporales, que escribió José E. García Fraguas (1894). Sorprende, que en esta obra de 1925, tan sólo se citara una obra nacional del siglo anterior y de treinta años atrás.

Así pues, percibimos que se observa una clara tendencia a infravalorar la mayoría de la producción bibliográfica española en favor de la extranjera, que era considerada, generalmente, como más apta. De igual modo sucede con el bibliógrafo Rufino Blanco, que salvada la excepcional Bibliografia General de la Educación Física (1927), en Pedagogía fundamental. Teoría de la educación (1930) incorporó una nómina de 240 referencias bibliográficas al final del capítulo XII "La educación Física". Entre las obras 
se citaban tanto autores extranjeros como nacionales, aunque entre éstos últimos tan sólo citó a doce. Debiera considerarse que siendo Rufino Blanco un erudito conocedor de la bibliografía de la educación física, solamente considerase a unos pocos autores. Probablemente, en opinión del bibliógrafo y pedagogo, ninguna de las aportaciones autóctonas fuese de interés, puesto que apenas citaba en el contenido de la obra autores españoles, sino más bien extranjeros como Tissié, Lagrange, Spitzy, Welpton, Boigey, Hebert o Brest. Los autores españoles citados son: Julián de las Barreras (1900), Isaías Bobo-Díez (1917), Cartilla de Gimnástica Infantil (1924), Santos Hernández (1907?), Victoriano Fernández (1915), Lorenzo Niño Viñas (1913), Juan Llongueras (1915), Alejandro San Martín (1893), Marcelo Sanz (1915), Rodrigo Suárez Álvarez (1925), Dr. Saimbraum (1912) y José Villalba (1927).

En 1932, el primer número de la revista dirigida por Augusto Condo La Educación Física $-2^{a}$ época- la sección "Biblioteca deportiva", ponía a la venta veintiocho obras francesas en idioma original de autores muy conocidos como Hebert, Boigey, Ruffier o Demeny. En el segundo número, la lista de las obras a la venta ya era de cincuenta. El dato curioso es que, a excepción de una obra, ninguna de ellas se había traducido hasta la fecha en España (Condo, 1932a y 1932b) ${ }^{5}$. Seguramente, uno de los objetivos de la revista consistía en cubrir el vacío bibliográfico español, mediante la incorporación de obras extranjeras en versión original. Asimismo, en 1935, la Librería Horizonte de Madrid Blasco Ibáñez, 55-, especializada en geografía, mapas, planos, guías, alpinismo, gimnasia y deportes, anunciaba en la revista Gimnástica, portavoz oficial de la Sociedad Gimnástica Española, obras en torno a la educación física publicadas en inglés, francés e italiano $\left(n^{\circ} 11\right.$, p. 29).

En el Diccionario de la Pedagogía de la Editorial Labor (1936, p. 1.018-1.027) al buscar la palabra "educación física", sucede otro tanto, sólo se localiza una obra española, curiosamente de Isaías Bobo-Díez, Educación física teoría y práctica (1917). En nuestra opinión se presentaba una obra completamente desfasada para la época en que se escribió y, todavía más, para que en 1936 fuese divulgada como referencia. De igual modo que en la Enciclopedia Universal Ilustrada de Espasa-Calpe (1925), el Diccionario de Labor sitúa en un menosprecio a la bibliografía española.

Como hemos comprobado en las pocas obras en que se incorporó alguna bibliografía, apenas se citaron autores españoles, sobresaliendo muchísimo más las referencias a autores extranjeros. Detectamos así, que existió menosprecio generalizado a la bibliografía autóctona.

En Barcelona, la Librería Sintes ofrecía un listado de obras de educación física Sports y Gimnasia que se encontraban a la venta en 1933. La librería pertenecía al menorquín Francisco Sintes Borras, un entusiasta de los libros, del periodismo y del deporte, que en 1914 animado por Josep Elías fundó la popular Biblioteca "Los Sports", primera librería y editorial especializada de España en temas de educación física y deporte (Balius, 1998; Torrebadella, 2009). El listado de la Librería Sintes consta de noventa y cuatro obras, 
entre las que se destaca, como curiosidad, el libro Ojeada de Gimnástica. Utilidades y ventajas que emanan de esta ciencia, del conde Villalobos que, editado en 1842, seguía aun a la venta en 1933 (Tey, 1933).

Igualmente, la bibliografía de la Librería Internacional de Romo consistía en un extracto compuesto por noventa y cuatro referencias de obras en castellano y de autores españoles y extranjeros en torno a la educación física y el deporte que la Librería Romo tenía a la venta en Madrid, c/ Preciados núm. 13 (Muller, 1936).

Estos listados fueron frecuentemente anunciados en apéndices añadidos al final de las diferentes publicaciones editoriales (Tey, 1933; Muller, 1936). Como repertorios o catálogos son una fuente directa de las librerías y reúnen un especial valor, puesto que facilitan la localización de obras que no fueron citadas en ninguno de los repertorios bibliográficos de la época, además que añaden la información comercial indicando qué obras estaban aún en venta. Ambas librerías ofrecieron conjuntamente, entre 1933 a 1936, 141 títulos, repartidos entre 61 obras, en torno a la educación física y/o sistemas gimnásticos y, 80 obras, en torno a prácticas deportivas. De las 61 obras de educación física, 35 fueron publicadas por autores extranjeros y de las obras deportivas tan solo aparecen 21 títulos $^{6}$.

Una carta con fecha de 18 de diciembre de 1934, firmada por el presidente de la Academia d'Educació Física de Catalunya, Carles Comamala, pedía al director de la Biblioteca de Cataluña, que tuvieran a bien en reponer nuevos libros sobre educación física, es decir sobre gimnástica y deportes, puesto que los pocos existentes habían perdido el valor por ser anticuados y publicados por autoridades de poco prestigio. Para lograr tal propósito la Academia d'Educació Física de Catalunya se ofreció para elaborar una lista de aquellos libros más a propósito para estudiar la materia ${ }^{7}$.

Ramón Fagella (1935) confeccionó un manuscrito en 1919, Salud higiene y educación física, siendo presentado en 1924 en el "Premio Pi i Suñer", promovido el concurso por la Associació Protectora de l'Ensenyança Catalana, que tenía por objeto dotar con mil pesetas, a la mejor cartilla escolar de educación física. El premio fue otorgado a Ramón Fagella, pero la obra no fue publicada hasta 1935.

En 1934, la Federación Catalana de Gimnástica promovió una campaña y un concurso con objeto de estimular la publicación de los primeros libros de gimnástica en catalán. La revista Gimnàstica abrió las bases de un concurso libre en el que se presentaron los señores Narcís Díaz, Juan Soler y Joaquim Ral (Noticiari, 1934, p. 25).

La misma revista anunciaba Assaig d'un pla d'Educació física, del Dr. Juan Soler, un volumen de más de trescientas páginas, del que decía ser, se convertiría en el primer libro de gimnástica escrito en lengua catalana. Como conocemos, esta obra no apareció hasta 1936, mostrándose incompleta (Torrebadella, 2000b). En este mismo año también se publicaba otra obra del Dr. Joaquim Ral, Resum d'Educació Física. En la revista 
Gimnàstica este autor presentaba algunos artículos que, según él, correspondían a un libro inédito: Per un Pla d'educació fisica. Joaquim Ral (1936) publicó posteriormente otro libro en catalán Resum d'educació física en la popular editorial Barcino. En esta obra el Dr. Ral -en el contexto de la educación física en Cataluña- denunciaba asimismo la escasez de bibliografía. Como constatamos, esta crítica también podría hacerse extensible para toda España: "Amb la present publicació -que ve a omplir una llacuna. Avui inexplicable, dins de la nostra bibliografia-voldriem contribuir a créixer l'interès de les juventuts catalanes vers aquestes sanes i nobles activitats" (Ral, 1936, p. 8).

La Guerra Civil paralizó prácticamente toda la empresa librera. Sin embargo, algunas pocas obras en torno a la educación física y el deporte fueron publicadas en ambos bandos (Torrebadella, 2011b).

En marzo de 1938, en Cataluña el Comisariado de Educación Física y Deportes todavía convocaba premios literarios con el objeto de incentivar propagandas morales y doctrinas de guerra. Así se concedía un premio de 1000 pesetas para el "autor o autora de la millor novel-la original i inèdita escrita en català d'ambient esportiu i relacionada amb l'actual guerra contra el feixisme que posi de relleu la importància que per al combatent representa una eficient preparació física". También destinaba otro premio de 300 pesetas "al combatent del millor compte original i inèdit escrit en català de caràcter social que més valori el paper de l'educació física en la plasmació de la nova Espanya que sorgeixi de la guerra contra el feixisme" (Generalitat de Catalunya..., 1938, p. 1).

\section{CONCLUSIONES.}

Singularmente, las referencias y las opiniones que hemos localizado en estas obras, nos ayudan a interpretar mejor el estado de la cuestión y apreciar la importancia que tuvieron estas pocas aportaciones para el desarrollo social e institucional de la educación física y la gimnástica en el desierto bibliográfico que las propias disciplinas generaban.

Como hemos tratado, la principal motivación de algunos autores consistió en llenar el vacío bibliográfico en la materia. Aunque también, en la mayoría de las obras se descubre un espíritu crítico, que se presenta con la intención de reclamar un espacio social para la educación física. Al respecto, se denunció el poco interés que despertaba en las autoridades públicas el llamado problema de la educación física, ya fuese en el ámbito higiénico, pedagógico, recreativo o militar.

Otras informaciones bibliográficas sobre la educación física española han provenido de los catálogos y/o apéndices que en los años treinta incorporaron algunas obras de tipo deportivo. Entre estas obras se pueden concretar algunas editadas por la Librería Sintes de Barcelona y, otras, por la Librería Internacional Romo de Madrid. Estos apéndices documentalmente son valiosos porqué validan el interés comercial y popular de las obras. 
Ante lo expuesto, podemos concluir a grandes rasgos, que la bibliografía de la educación física española resultó generalmente escasa, simplista y carente de originalidad, siendo además fuertemente influenciada por la bibliografía extranjera.

Nuestra bibliografía nacional propia no fue lo suficientemente valorada por las autoridades académicas y científicas y fue en gran medida una producción anecdótica y circunstancial. Lamentablemente, la bibliografía de la educación física y la gimnástica ya fuera de tipo técnico o de alcance popular, no recibió el apoyo institucional que hubiera sido de desear.

\section{NOTAS.}

${ }^{1}$ En lo que se refiere a autores extranjeros, se citaban importantes nombres de la panorámica gimnástica europea: Guts Muths (1793), Amorós (1830), Ling (1840), Nyblaeus (1864), Spiess (1840), Laisné (1854), Heiser (1854), Paz (1876), Clias (1816 y 1829), Tissot (1870), etc., etc.

${ }^{2}$ Las referencias españolas son Mercurial (1845), Aparici (1852), Busqué (1865), Carlier (1867), Paz (1867), López (1873), Schreber (1873) y Lladó (1876).

${ }^{3}$ Anótese que se han incorporado los años de las citadas obras que el autor omitió. Vid. Torrebadella (2011b).

4 Amorós (1820), Pichery (1864), Heiser (1875), Paz (1880), Lauret (1882), Hoffman (1882), Le Blond (1887), Dujardin-Beaumentz (1888), Pichery (1890), Désire Shéhe (1890), Cruciani (1892) y Laisne (1892).

${ }^{5}$ La obra de excepción es Le sport contre l'education physique de G. Hebert (1925).

${ }^{6}$ Los autores de estas obras extranjeras son: Atkinson y Beals, Blaikie, Boigey, Demeny, Franklin y Clinton, Gelly, Gilbert y Carnot, Henslowe, Herbert, Jentzer, Kumlien, Marquebreucq, Masters, Mossó, Muller, Pages y Casteyre, Parnet, Paz, Ramacharaka, Ruffier, Soleirol y Le Roux, Spitzy, Thulin, Trachet, Vander, Weismuhler, Weltom, Wenzel, Zar-Adusht Hanis.

7 Arxiu Administratiu Històric de la Biblioteca de Catalunya, 1907-1986. Academia d'Educació Física de Catalunya, 1934-1935 (2c) Ref. 90/2.

${ }^{8}$ El prólogo de la obra está escrito por Agust Pi i Suñer en enero de 1931.

\section{BIBLIOGRAFÍA.}

AGUILERA OSORIO, J. Memoria sobre la organización de la educación física en Francia, Alemania, Suecia e Italia. Madrid: Imp. Lib. y Casa Ed. Hernando, 1928.

ALFONSO, E. Cómo cura la medicina natural. Divulgación teórica y práctica del método higio-terapéutico, naturista o hipocrático ( $3^{a}$ ed.). Madrid: Editorial Pueyo, s.a., 1925.

ÁlVAREZ BUYLLA, A. El libro de M. Daryl sobre educación física (fragmentos de un estudio). BILE, 1890, no 313, p. 50-54.

ÁlVAREZ GARCÍA, A. Manual de gimnástica militar. Granada: Imp. Paulino V. Sabatel, 1889.

AMAT ZESVAS, C. Nociones de gimnástica. Lérida: Rauret, 1859.

AMOROS, F. Manuel d'éducation physique, gimnastyque et morale. Paris: Rouret, 1830.

ARENAL, C. La instrucción del pueblo. Observaciones sobre la educación física, intelectual y moral de Herbert Spencer. La instrucción del obrero y la Educación de la Mujer. Madrid: Lib. de Victoriano Suárez, 1929. 
BALIUS JULI, R. La biblioteca los sports. Apunts d'Educació Física i Esports, 1998, nº 52, p. 109-113.

BEJARANO, E. Educación física. El Genio Médico-Quirúrgico. 31 de enero de 1886, nº 1.501, p. 53-54.

BERASATEGUI DOLCET, M.L. Amadeu Llaverías, Gimnàsta i bibliòfil. Apunts d'educació Física i Esports, 1998, nº 53, p. 98-102.

BERASATEGUI DOLCET, M.L. Fonts bibliogràfiques per a l'estudi de l'educació física i l'esport a Catalunya (1856-1975). Temps d'Educació, 2008, no 35, p. 169-196.

BLANCO SÁNCHEZ, R. Bibliografía General de la Educación Física. Madrid: Imp. Hernando, 1927.

BLANCO SÁNCHEZ, R. Pedagogía fundamental. Teoría de la educación. Madrid: Lib. y Casa Ed. de Hernando, 1930.

BOBO-DÍEZ, I. Educación física teoría y práctica. Valladolid: Imp. Viuda Montero, 1917.

BUSQUÉ TORRÓ, S. Gimnástica higiénica, médica y ortopédica o el ejercicio considerado como medio terapéutico. Madrid: Imp. Manuel Galiano, 1865.

CAMPO, J. Elementos de educación física. Palma: Imp. de Pedro J. Gelabert, 1878.

CARLIER, P. Tratado de gimnasia médica y civil. Santander: González, 1867.

CARRASCAL MARTÍN, B. Algunas consideraciones sobre educación física, estudiadas principalmente desde el punto de vista fisiológico. Madrid: Imp. de G. Hernández y Galo Sáez, 1923.

CASAS CASANY, A. Ensayos. Algo de pedagogía. La educación fisica en la escuela. Valencia: Est. Tip. de Manuel Pau, 1910.

CLIMENT BARBERÁ, J.M. Historia de la rehabilitación médica. De la física terapéutica a la reeducación de inválidos. Barcelona: Edika Med, 2001.

CLIMENT BARBERÁ, J.M. La gimnasia médica en la España del siglo XIX. Formulación del concepto de rehabilitación en la obra de Sebastián Busqué Torró. Departamento de Historia de la Ciencia y Documentación de la Universidad de Valencia, 1989.

CONDO, A. Biblioteca de Educación Física. La Educación Física, 1932a, no 1, p. 34.

CONDO, A. Biblioteca de Educación Física. La Educación Física, 1932b, no 2, p. 35.

CONDO, A. Fisiología y deportes. La Educación Física, 1919, no 5, p. 30-31.

CORTADA ANDREU, E. Un precedent en l'educació física de les nenes. La proposta de Pilar Pascual de Sanjuán des de les pàgines de El Monitor de primera Enseñanza. En 14è Congrés Internacional Educació, Activitats Físiques i Esport en una perspectiva històrica, Barcelona del 3 al 6 de setembre de 1992, Barcelona: Ed. Jordi Monés i Pere Solà, 1992, p. 261-267.

CRIADO DOMÍNGUEZ, J.P. Literatas españolas del siglo XIX. Apuntes bibliográficos. Madrid: Imp. Antonio Pérez Dubrull, 1889.

DALMAU, A.R. El circo en la vida barcelonesa. Crónica anecdótica de cien años circenses. Barcelona: Ediciones Librería Milla, 1947.

DEPORTES, Los. Regalo a nuestros lectores. Los Deportes, 1906a, nº 426, p. 734.

DEPORTES, Los. Regalo a nuestros lectores. Los Deportes, 1906b, nº 426, p. 710. 
ESPASA-CALPE (Ed.). Enciclopedia Universal Ilustrada Europeo-Americana, t. XXVI. Madrid: Espasa-Calpe, 1925.

FAGELLA, R. Salut i educació física. Barcelona: Publicacions de l'Editorial Pedagògica Associació Protectora de l'Enseyança Catalana, 1935.

FERNÁNDEZ VILLABRILLE, F. Instrucción para el pueblo, Cien tratados sobre los conocimientos más útiles e indispensables. Gimnástica, Entrega 72, tratado 63, Madrid: Est. Tip. de Mellado, s. a. 1849.

FIGUEROLA, L. Guía legislativa e inspectiva de instrucción primaria. Madrid: Librería Europea de Hidalgo, 1844.

FLECHA GARCÍA, C. El carácter médico-higiénico de la gimnástica en el siglo XIX. En 14è Congrés Internacional Educació, Activitats Físiques i Esport en una perspectiva històrica, Barcelona del 3 al 6 de setembre de 1992, Barcelona: Ed. Jordi Monés i Pere Solà, 1992, p. 268-273.

FUSTÉ ESCUDÉ, J. Breu notícia del Gimnàs de Colon de Barcelona. En La formació inicial i permanent dels mestres, Actes de la XIII Jornades d'Història de l'Educació als Països Catalans. Vic: Ed. Eumo, Vic, 1997, p. 243-254.

Gacetilla de la capital. El Heraldo, 4 de noviembre de 1845, p. 4.

GARCÍA FRAGUAS, E. Programa razonado de gimnástica higiénica y juegos escolares para la Universidad, Instituto y Escuela Normal de Salamanca. Salamanca: Imp. de Francisco Núñez Izquierdo, s.a., 1892a.

GARCÍA FRAGUAS, J.E. Historia de la gimnástica higiénica y médica. Madrid: Est. Tip. de Ricardo Fé, 1892b.

GARCÍA FRAGUAS, J.E. Tratado racional de ejercicios y juegos corporales, (t. I). Madrid: Est. Tip. Enrique Rubiños, 1893.

GARCÍA FRAGUAS, J.E. Tratado racional de ejercicios y juegos corporales, (t. II). Madrid: Est. Tip. Enrique Rubiños, 1894.

Generalitat de Catalunya. Departament de Cultura. Comissariat d'Educació Física i Esports. Concursos Literaris, L'autonomista: Diari d'Esquerra (Girona), 23 de març de 1938, p. 1.

Gimnasia. Los Deportes, 1906a, no 432, p. 894-895.

Gimnasia. Los Deportes, 1906b, nº 433, p. 917.

GONZÁLEZ, F. Educación física en el hombre. Necesidad de promoverla en España por las madres, y escuelas públicas de enseñanza. Madrid: Imp. Sancha, 1814.

GUTIÉRREZ RODILLA, B.M. La gimnástica del bello sexo. Una avanzadilla de la introducción de higiene en español. En Actas del XXXIII Congreso Internacional de Historia de la Medicina. Sevilla: Sociedad Española de Historia de la Medicina, 1994, p. 1039-1049.

GUTIÉRREZ RODILLA, B.M. Los primeros pasos de la gimnástica en España (17801850). En ARQUIOLA, E. y Martínez, J. (Coord.). Ciencia en expansión. Estudios sobre la difusión de las ideas científicas y médicas en España (s. XVIII-XX). Madrid: Universidad Complutense, 1995, p. 421-447.

HEBERT, G. Le sport contre l'education physique. Paris: Vrin, 1925. 
HERNÁNDEZ VÁZQUEZ, J.L. Los aparatos de Amorós y su influencia en la gimnástica española del siglo XIX. En Seminario Francisco Amorós, su obra entre dos culturas. Madrid: INEF, 1988, p. 30-63.

La gimnasia del bello sexo o ensayo sobre la educación física de las jóvenes $\left(2^{\mathrm{a}}\right.$ ed.). Londres: R. Ackermann, 1827.

LABOR (Ed.). Diccionario de la Pedagogía. Barcelona: Editorial Labor, 1936.

LAGRANGE, F. Ejercicio en los adultos. Madrid: Imp. Gregorio Juste, 1896.

LAGRANGE, F. Fisiología de los ejercicios corporales. Madrid: Imp. Gregorio Juste, 1895.

LAGRANGE, F. La higiene de los ejercicios en los niños y en los jóvenes. Madrid: Imp. José Jorro, 1894.

LETAMENDI, J. La gimnástica cristiana. Barcelona: Imp. Jaime Jesús Roviralta, 1876.

LÓPEZ GÓMEZ, S. El gimnasio. Sevilla: Imp. R. Baldaraque, 1873.

LÓPEZ GÓMEZ, S. Manual de ejercicios gimnásticos: para uso de los Institutos y Escuelas Normales. Sevilla: Imp. Gironés y Orduña, 1894.

LLADÓ, J. Nociones de gimnasia higiénica. Barcelona: Antonio J. Bastinos, 1868.

LLAVERÍAS ROVIROSA, A. Catálogo de la Biblioteca del Gimnasio de Colón. Barcelona: Imp. Fiol, 1910.

LLAVERÍAS, A. Catálogo de la Biblioteca Gimnástico - deportiva y de conocimientos afines. Barcelona: Anticuaria de Antonio Palau Dulcet, 1935.

LLAVERÍAS, A. Biblioteca Gimnástica del Gimnasio de Colón. Los Deportes, 1905a, nº 366, p. 547-555.

LLAVERÍAS, A. Gimnasio de Colón. Los Deportes, 1905b, nº 368, p. 282.

MARÍN GARCÍA, E.D. Marcelo Sanz Romo, iniciador y propagandista de la educación física en España: Vida y obra. Universidad de Alcalá, Departamento de Didáctica, 2009 [Tesis doctoral no publicada].

MASFERRER, N. Estudio de la gimnástica. Los Deportes, 1902, nº 35, p. 541.

MONLAU, P.F. Elementos de higiene privada. Barcelona: Imp. de Pablo Riera, 1846.

MORATONES FREIXA, A. Nociones elementales de gimnasia, para jóvenes de ambos sexos. Barcelona: Imp. Joaquín Bosch, 1863.

MOSSO, A. La educación física de la juventud. Madrid: Jorro, 1894.

MULLER, J.P. Cinco minutos diarios para conservar la aptitud fisica y la mejor base de entrenamiento para ambos sexos. Madrid: Librería Internacional Romo, 1936. [Contiene un apéndice de la Bibliografía librería Internacional de Romo].

Museo Pedagógico Nacional. Notas sobre material de enseñanza. Madrid: R. F. de Rojas, 1915.

Noticiari. Gimnàstica, 1934, nº 2, p. 25.

Noticias generales. La Época, 14 de diciembre de 1853, p. 2-3.

ORDAX, M. El Conde de Villalobos. El Gimnasio, 1882, $\mathrm{n}^{\circ}$ 1, p. 10-11.

PALAU, A. Llibreria Antiquaria de Antonio Palau. Catàleg núm. 27. Barcelona: Imp. Ràfols, 1925.

PASCUAL, P. Importancia de la educación física de las niñas. Memoria premiada en el segundo Certamen Pedagógico. Granada: "El profesorado de Granada", 1880. 
PAZ, E. Gimnasia razonada. Madrid: Talleres tipográficos Stampa, 1917. [Prólogo del traductor Ricardo Ruíz Ferry].

PAZ, E. La salud del espiritu y del cuerpo por la gimnasia. Murcia: Imp. Anselmo Arques, 1867.

PEDREGAL, F. Gimnástica civil y militar. Madrid: Tip. M. Ginés Hernández, 1884.

PEDREGAL, F. La educación gimnástica. Madrid: Imp. Hijos de M. G. Hernández, 1895.

PIERNAVIEJA, M. La educación física en España: Antecedentes histórico legales. Citius, Altius, Fortius, 1962, t. IV, p. 5-150.

Publicaciones importantes. El Gimnasta Español, 1882a, nº 1, p. 7.

Publicaciones importantes. El Gimnasta Español, 1882b, nº 2, p. 7.

Revista bibliográfica. El Imparcial, Revista Hispano-Americana, 1867, no 3, p. 83-84.

RAL BANÚS, J. Resum d'educació física. Barcelona: Ed. Barcino, 1936.

RAMÍREZ, F. de B. Elementos de gimnasia. Madrid: Imp. F. Ventura y Sabatel, 1856.

RAMIS TAIX, J. Programa de Gimnasia en general y de la gimnasia higiénica, médica y utilitaria. Barcelona: Est. Tip. Ed. "La Academia", 1888.

SÁNCHEZ SOMOANO, J. Tratado de gimnasia pedagógica para uso de las escuelas de primera y segunda enseñanza e institutos. Madrid: Imp. Vda. de M. Minuesa de los Ríos, 1883.

SÁNCHEZ SOMOANO, J. Gimnástica Escolar, Juegos Calisthémicos. Madrid: Imp. Minuesa de los Ríos, 1894.

SANZ ROMO, M. Sport de la infancia y de la juventud. Manual de gimnástica higiénica y juegos escolares. Madrid: Imp. Sucesores de Cuesta, 1895.

SCHREBER, D.G.M. Manual popular de gimnasia de sala. Madrid: Carlos Bailly Bailliere, 1861.

SERRATE, F. La Ilustración Gimnástica. Madrid: Dirección General de Deportes de la Comunidad de Madrid, 1999. [Introducción a cargo de Manuel Vitoria].

SERRATE, F. Tratado teórico-práctico de los principios y reglas de aplicación de la gimnástica médica, higiénica y ortopédica y todo cuanto se relaciona con la educación física. Bilbao: Est. Tip. Viuda de Delmás, 1887.

TEY ENRICH, M. Lawn tennis. Barcelona: Lib. Sintes, 1933. [Obras de educación física Sports y Gimnasia]

TISSIÉ, P. La fatiga y el adiestramiento fisico. Madrid: Imp. Lib. E. Rojas, 1899.

TORREBADELLA FLIX, X. Aproximació a una història de l'activitat física i l'esport mitjançant l'anàlisi de les fonts bibliogràfiques (1800-1939). Apunts Educació Física $i$ Esports, 2000a, no 59, p. 11-20.

TORREBADELLA FLIX, X. Contribución a la historia de la educación física en España. Estudio bio-bibliográfico en torno a la educación física y el deporte (18001939). Universitat de Lleida, Departament d'Història de l'Art i Història Social, 2009. [Tesis doctoral no publicada].

TORREBADELLA FLIX, X. L'esport català durant la Segona República: el Comissariat d'Educació Física i Esports de la Generalitat de Catalunya. Barcelona: Col-legi de Llicenciats en educació Física i Ciències de l'Activitat Física i de l’Esport de Catalunya, 2000b. 
TORREBADELLA FLIX, X. La educación física y la actividad gimnástico-deportiva de las mujeres a partir de la bibliografía especializada del siglo XIX, 2011a, Arena, vol. $18, \mathrm{n}^{\mathrm{o}} 1$, p. 147-179.

TORREBADELLA FLIX, X. Repertorio bibliográfico inédito de la educación física y el deporte en España (1800-1939). Madrid: Fundación Universitaria Española, 2011b.

TORREBADELLA FLIX, X. Vicente Naharro y los juegos corporales en la educación física española de la primera mitad del siglo XIX. Ágora para la Educación física, 2011c, n⿳⺈ 13 , p. 165-182.

TORREBADELLA FLIX, X. Las primeras revistas profesionales y científicas de la educación física española, 1882-1936. Apunts Educació Física i Esports, 2012a, no 109 , p. 11-24.

TORREBADELLA FLIX, X. Las primeras tesis doctorales de la educación física en el espacio científico y profesional sobre la medicina española. Pecia Complutense, $2012 \mathrm{~b}, \mathrm{n}^{\mathrm{o}} 16, \mathrm{p} .58-88$.

TORREBADELLA, X. y OLIVERA, J. Las cien obras clave del repertorio bibliográfico español de la educación física y el deporte en su proceso de legitimación e institucionalización (1807-1938). Revista General de Información y Documentación, 2012, n' 22, 119-168.

Un concurso útil. Crónica del Sport, 1894, tomo II, nº 4, p. 55.

VILLALBA, J. Organización de la Educación física e Instrucción militar en Francia, Suecia, Alemania e Italia. Madrid: Talleres del Depósito de la Guerra, 1927.

VILLALOBOS, conde de. Ojeada sobre la Jimnasia, utilidades y ventajas que emanan de esta ciencia. Madrid: Imp. de Yenes, 1842.

VILLALOBOS, conde de. Representación del señor D. Francisco Aguilera, conde de Villalobos, acerca de la formación de un Gimnasio Normal en Madrid. Madrid: Imp. Colegio de Sordomudos y Ciegos, 1845.

VILLALOBOS, conde de. Reseña histórica del Gimnasio Real de Madrid. (Continuación). Revista de Sanidad Militar Española y Extranjera, 1865, no 34, p. 253-261.

VILLALOBOS, conde de. Sobre gimnasia. La Razón Católica, 1858, nº 4, p. 259-266. 